\title{
Analysis of controllers in suppressing the structural building vibration
}

\author{
Normaisharah Mamat", Fitri Yakub, Sheikh Ahmad Zaki Sheikh Salim \\ Malaysia-Japan International Institute of Technology, Universiti Teknologi Malaysia, Kuala Lumpur, Malaysia \\ * Corresponding author: normysarahmn@gmail.com
}

Article history

Submitted 27 February 2018

Revised 28 March 2018

Accepted 21 May 2018

Published Online 4 February 2019

\begin{abstract}
Two degree of freedom (2 DOF) mass spring damper system is used in representing as building structure that dealing with the earthquake vibration. The real analytical input is used to the system that taken at El Centro earthquake that occurred in May 1940 with magnitude of $7.1 \mathrm{Mw}$. Two types of controller are presented in controlling the vibration which are fuzzy logic (FL) and sliding mode controller (SMC). The paper was aimed to improve the performance of building structure towards vibration based on proposed controllers. Fuzzy logic and sliding mode controller are widely known with robustness character. The mathematical model of two degree of freedom mass spring damper wasis derived to obtain the relationship between mass, spring, damper, force and actuator. Fuzzy logic and sliding mode controllers were implemented to 2 DOF system to suppress the earthquake vibration of two storeys building. Matlab/Simulink was used in designing the system and controllers to present the result of two storeys displacement time response and input control voltage for uncontrolled and controlled system. Then the data of earthquake disturbance was taken based on real seismic occurred at El Centro to make it as the force disturbance input to the building structure system. The controllers proposed would minimize the vibration that used in sample earthquake disturbance data. The simulation result was carried out by using Matlab/Simulink. The simulation result showed sliding mode controller was better controller than fuzzy logic. In specific, by using the controller, earthquake vibration can be reduced.
\end{abstract}

Keywords: Fuzzy logic, sliding mode controller, vibration, earthquake

\section{INTRODUCTION}

A study on vibration controls has been done many years ago since it can help in reducing the effect of nature forces to buildings. Natural disaster nowadays such as earthquake may cause fear to structural engineers to build safer building. The largest earthquake magnitude was happened at Vildivia, Chile with 9.5 moment magnitude $(M w)$ in 1960 that caused a lot of damages and 6000 people were died. The other example of earthquake was occurred at Xining, China with magnitude 7.9 Mw and caused 40,900 people died. This largest dead had occurred because of over 500 schools and buildings are damaged (EarthquakeReport). The controlling devices have been introduced to solve the problem of environmental disturbance such as passive and active device since last 3 decades. The method of using passive control is difficult to control the structure in several vibration modes. This method does not use any external power and building vibration is reduced by changing the frequency of the structure. The example of passive device is Tuned-mass damper (TMD) that suppresses vibration of the structure. TMD is used in suppressing and reducing vibration especially in earthquake induced vibration (McNamara, 1977). It is placed on the top of the buildings and used to minimize the amplitude of vibration by absorbing kinetic energy produced by the system. During earthquake or wind disturbance, the damper from TMD will minimize the structure swing by absorbing the structure disturbance. The example of building that used this passive controller is Taipei 101 tower. However the performance of passive control is limited since it cannot retune to external load changes and the characteristic over time. This problem can be solved by using the method of active control (Fallah \& Ebrahimnejad, 2013).

Active control is a system that needs a large power source to increase the structural stiffness or damping by using hydraulic or electromechanical actuator. The working principle of active control system is by measuring the control algorithm of the structural response. Then the algorithm will produce the control signal that required to attenuate the vibration and cause the actuator to generate secondary vibrational response that can reduce the response of the structure (Thenozhi \& Yu, 2013). The structure of active control is classified based on the mathematical modelling such as linear control (when all the mathematical equations and operations are linear), nonlinear control (where the operation is non-linear), time varying control (when the control function and parameter are varied with time), discrete time control system (when the control parameter is varied at discrete time intervals), lumped parameter control system (when the control parameters are lumped), distributed control parameter system (when the parameters are function of space), deterministic control system (when all mathematical operations are deterministic) and stochastic control system (when the mathematical equations and operations are stochastic) (Datta, 2003). The types of actuator, structural parameter and design criteria for damping, mass and stiffness play important factors in influencing the optimal placement of actuator in a building structure (Liu, Yang, \& Li, 2003). Active control has advantageous for controlling the vibration of building structure based on controlling wide frequency range. The concept of 
this method is introduced in early 1970 s and then the application of this method is produced in 1989 (Thenozhi \& Yu, 2013).

In 1972, Yao proposed structural active control and then many engineering experiments demonstrated structural active control in reducing damage that caused by earthquake (Maria, Selvaganesan, Kumar, \& Kapoor, 2015). This active device has capabilities in adding force to the building structure. The description between passive and active control was proposed by Keiji et al. (1998) in 1997 by using the example of unbounded brace damper mechanism as passive control and hybrid mass damper as active control system that were installed at the top floor with fifteen storeys building. The simulation result showed the effectiveness of the control device during strong winds. The paper by (Yi \& Dyke, 2000) also studied about these two types of control by comparing between them. The simulation used $\mathrm{H}_{2}$ and LQR control algorithm and the result showed that active and passive control systems have the same performance towards the structure. However, the system used single DOF and the result for the system structure with multiple DOF showed active control has higher performance compared to passive control (Yi \& Dyke, 2000).

The controller plays the role in generating the stable dynamics to prevent the building damages. Many types of controllers are studied nowadays for implementation to the system. One of the examples is proportional integral derivative (PID) controller. This type of controller is used because of its simple and has clear physical meaning. In structural vibration control application, PID is still not well developed although this type of controller is already established in research fields (Yu, Thenozhi, \& Li, 2014). Thenozhi et al.(2014) used PID and Proportional Derivative (PD) in their paper to obtain the stable control performance of the building structure and the experiment was successfully reduced the displacement. However this paper only focused on two controllers which were sliding mode controller (SMC) and fuzzy logic controller. These two types of controller were chosen because of their robustness.

Emelyanov and other researchers were the first ones to propose sliding mode control (SMC) in early 1950s by using SMC with variable structure control (VSS) (Emelyanov, 1959). Then, in 1977 Utkin proposed SMC concept to American control researchers. After that, various applications of sliding mode control are used such as aerospace, robotics, automotive and process control (Sambariya \& Gupta). However the problem in using this method is the chattering that can cause damage to the mechanical component. This problem is solved by Sabanovic by producing the application with free chattering (Guclu, 2006). The paper proposed by (Guclu, 2006; Maria et al., 2015) used this type of controller. Paper by (Maria et al., 2015) implemented Linear quadratic regulator in designing sliding surface and Gao's power rate reaching law in designing the control to study the effectiveness of controller in suppressed the structural vibration. Guclu (2006) applied SMC in three-storey building and presented Lyapunov function to obtain the stability criteria. The Lyapunov stability criteria must be satisfied to obtain stable solution of the structure building. The simulation result based on both papers showed that SMC was highly reduced the displacement position of building structure for each floor. SMC can be realized by designing based on two steps. Firstly is by designing the sliding surface and then followed by designing control law. Control law design is based on suitable sliding surface that makes the system confined to the desired sliding and then the design is forced the system trajectory to maintain it there.

Fuzzy logic is first presented by Zadeh in 1965 by publishing his "Fuzzy Sets" to technical society (GÜÇLÜ, 2003). Fuzzy logic is stated to be a product of rational thinking and used the concept of 'IFTHEN' rules of inference by Dimitrov. The advantages of fuzzy logic are its characteristic that is easy to implement because of its semantic feature in the statement of control rules and has lower performance loss when controlled time varying parameters and nonlinear system. Besides that, fuzzy logic has simple computation in driving the controller. The motion for control equation in fuzzy logic is solved by using Matlab. The application called Fuzzy tool boxes is provided under Simulink application (Datta, 2003). The paper proposed by (Gioncu \& Mazzolani, 2010; GÜÇLÜ, 2003; Jing-Jun, Li-Ya, \& WeiZe, 2009; Schnable et al., 2009; Sharma \& Singh, 2014) used fuzzy logic controller in their simulation by using various types of rules. The analysis of different numbers, sizes and shapes of triangular membership function can cause the effect of response to the system (Schnable et al., 2009). The sets of fuzzy are represented the unique linguistic expression such as positive, zero, normal, small or negative. Four components are needed to be considered before generating the desired output in designing fuzzy logic controller. First component is fuzzifier, second is knowledge in rules and membership function, third is fuzzy reasoning and lastly is defuzzifer interface (Sharma \& Singh, 2014). The study by Xiuyan proposed that the error $e$ was used as general fuzzy controller design to produce its change rate holder with different value. The system with single input and single output can generate the output of error value which can be separately taken as displacement of the structure, acceleration and velocity responses. The control system with two inputs and one output will generate displacement speed, displacement acceleration and velocity acceleration (Zhang, 2010).

The aim of this paper wasto improve the building position during earthquake by using two controllers, fuzzy logic and sliding mode controller in order to obtain the best performance in reducing the earthquake vibration. The contribution of this paper was by using the real earthquake data input to the mass spring damper system and comparing the system without and with controller. This paper used the input of earthquake ground motion to the building system. The data of earthquake ground motion wasis used from the El Centro earthquake that occurred in 1940 with magnitude of $7.1 \mathrm{Mw}$ that caused 9 people dead (Gioncu \& Mazzolani, 2010).

This paper was organized by constructing mass spring damper system structure and linear actuator by using the mathematical model at section 2. Then in section 3, two types of controller were designed to implement to the system. In Section 4, the design procedure was described to show the parameters involved and the simulation result that obtained from Simulink was discussed. Last section was the conclusion from the simulation.

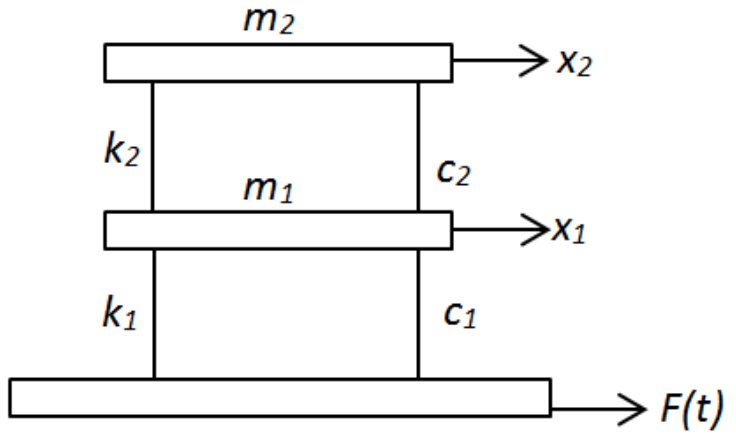

Fig. 1 Schematic of two storeyed building.

\section{Mass spring damper system model}

Two degree of freedom mass spring damper was presented as structural system building. Each floor in the structure wasis represented as one degree of freedom system. An earthquake caused the ground motion is called seismic wave, making the building structure to oscillate. The vibration of the structure may cause by several factors such as ground motion, the structure dynamic properties, the structure material characteristics and soil structure interaction. In this model, only horizontal vibration was considered due to earthquake effect occurred in horizontal vibration (GÜÇLÜ, 2003). Besides that, the model was assumed that the structure mass was concentrated at each floor and the gravity floor was neglected. The structure of the system was shown in Figure 1 with $m_{l}$ and $m_{2}$ is represented mass at each floor. The system structure was consisted of linear motor that functioned as active isolator, has been installed at the first floor since the largest destructive usually occurred at this floor. $k_{l}$ and $k_{2}$ are represented as spring stiffness while $c_{1}$ and $c_{2}$ are represented damping coefficient, $x_{1}$ and $x_{2}$ are the displacement of each floor that will change during earthquake occurrence in horizontal direction and $F(t)$ is the total force of the structure. The spring and dampers in the system were all moving in horizontal direction. The 
dynamic equations of two degree of freedom mass spring damper system were shown in Equation (1) and (2).

$$
\begin{aligned}
& m_{1} \ddot{x}_{1}+\left[c_{1}+c_{2}\right] \dot{x}_{1}-c_{2} \dot{x}_{1}+\ddot{x}_{1}+\left[k_{1}+k_{2}\right] \dot{x}_{1}-k_{2} x_{2}=F(t) \\
& \mathrm{m}_{2} \ddot{\mathrm{x}}_{2}-\mathrm{c}_{2} \dot{\mathrm{x}}_{1}+\mathrm{c}_{2} \dot{\mathrm{x}}_{2}+\mathrm{k}_{2} \mathrm{x}_{2}-\mathrm{k}_{2} \mathrm{x}_{1}=0
\end{aligned}
$$

The important part in controllability and observability of the system is the actuator. So the placement of actuator is important to obtain the minimum vibration of the building. The paper by (Amini \& Tavassoli, 2005; Güney \& Eşkinat, 2008) proposed various placement of actuator at the structure in their paper since the actuator placement might cause the effect to the vibration of building structure system. However, in this paper an actuator was placed on the first floor. This is because the largest destructive was expected to be occurred at the first floor.

The equations of linear actuator that applied in the first storey wereis shown in (3) and (4) (EarthquakeReport, 2016). This linear actuator acted as active isolator that would provide voltage directly to suppress the magnitude of undesirable earthquake vibrations. $u$ is represented as armature coil voltage, $I$ is armature coil current, $R$ is armature coil resistance value, $K e$ is armature coil induced voltage, $F u$ is output force by linear actuator, $K_{f}$ is thrust constant, $B$ is damper damping coefficient and armature coil inductance is neglected.

$$
\begin{aligned}
& R i+K e\left(\dot{\mathrm{x}}_{2}-\dot{\mathrm{x}}_{1}\right)=u \\
& F u=K_{f} i
\end{aligned}
$$

\section{Controller design}

The paper used two controllers in comparing the performance of vibration structure by measuring the effectiveness of the controllers to the system. The main objective in designing the controller was to reduce the movement of the building structure to the comfortable level.

\section{Sliding mode controller}

Sliding mode control is a type of robust control that easy to implement. The controller design consists of two methods. The first step is by designing switching function to obtain sliding motions according to design specifications. Then, the control law is selected in order to make the switching function attracted to the system state (Sharma \& Singh, 2014). The equation for sliding surface, $s$ as mentioned in (5) where $c$ is constant value greater than zero.

$$
S=c e+\dot{e}
$$

This paper used proportional switch law in designing the controller $u$. The equation is as below:

$$
u=(\alpha|e|)+\beta[\dot{e}\rceil) \operatorname{sgn}(s)
$$

where $e$ is error, $\alpha$ and $\beta$ are constant value greater than zero. The closed loop diagram of mass spring damper system with controller and actuator was presented as shown in Figure 2. Where $X_{\text {ref }}$ is the desired value for the system output and this value is set to 0 so that the building will remain at its position. $e(t)$ is error value calculated by the desired value minus with the actual value, then the controller will produce control signal value. Actuator produces force signal to the building and lastly, the system will produce the desired displacement position for the first floor and the second floor building.

The block diagram of sliding mode controller that used in designing in Matlab was based on equation (6) as shown in Figure 3.

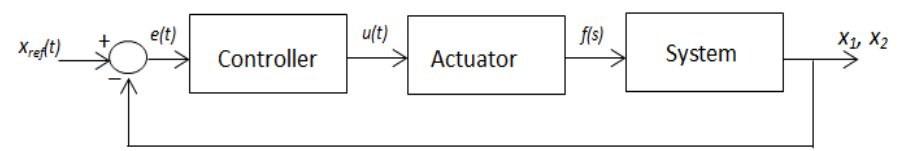

Fig. 2 Closed loop block diagram with the controller.

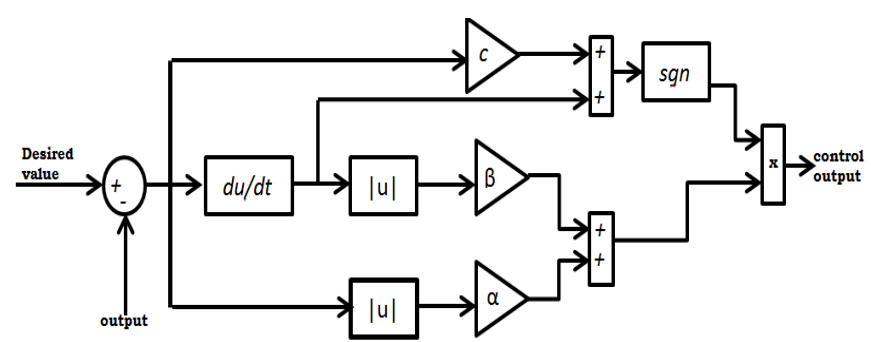

Fig. 3 . Sliding block diagram in Simulink.

\section{Fuzzy logic controller}

The paper used Fuzzy Toolbox in Simulink and designed based on double input and single output system. This controller used Mamdani method. The aim of the fuzzy logic control was to use the errors in the first story motion $\left(e=x_{r e f}-x l\right)$ and the derivatives (de/dt) of its input variable while controlling force $(u)$

was the system output. The figure for fuzzy logic control that implemented the system was shown in Figure 2. The input variable as shown in Figure 4, 5 and 6 . The input variable limited for displacement error (e) was $\pm 0.015 \mathrm{~m}$ and limit for velocity error (de/dt) was $\pm 3.5 \mathrm{~m} / \mathrm{s}$ while the limit for control force $(u)$ was \pm 8.8 . These limitation values were obtained by using trial and error until the desired output was obtained. The rule based for fuzzy logic controller wasis shown in Table 1, where $\mathrm{P}, \mathrm{N}, \mathrm{Z}, \mathrm{B}, \mathrm{M}$, and $\mathrm{S}$ were represented positive, negative, zero, big, medium, and small. In achieving a good controller performance, only a technique of trial and error with triangular membership functions was used as designed in paper proposed by (GÜÇLÜ, 2003).

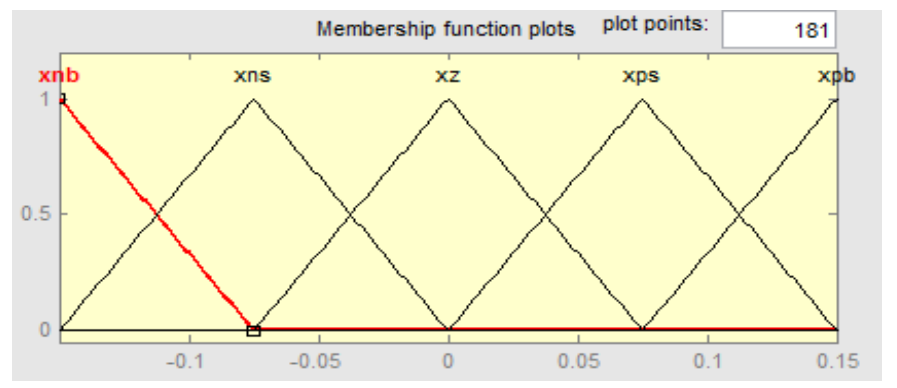

Fig. 4 Input variable "e".

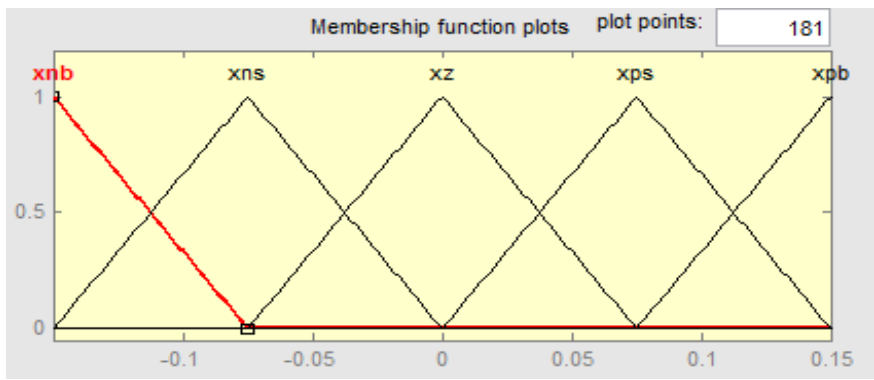

Fig. 5 Input variable de/dt.

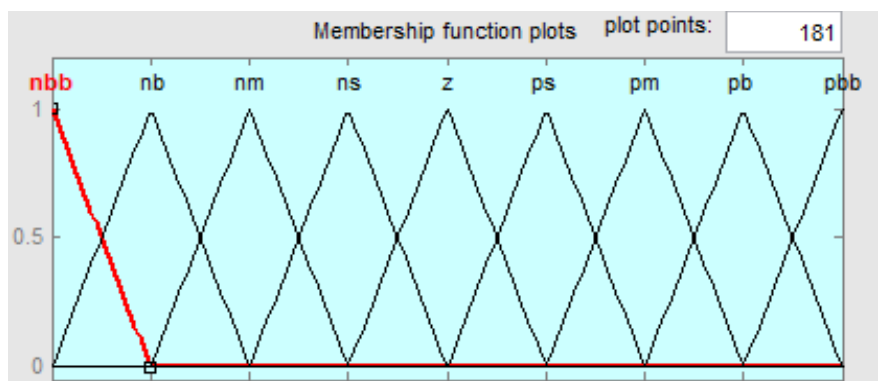

Fig. 6 Output variable " $u$ ". 
Table 1 Rule base for fuzzy logic controller.

\begin{tabular}{cccc}
\hline & VN & VZ & VP \\
\hline XNB & UNB & UNM & UNS \\
XNS & UNM & UNS & UZ \\
XZ & UNS & UZ & UPS \\
XPS & UZ & UPS & UPM \\
XPB & UPS & UPM & UPB \\
\hline
\end{tabular}

\section{RESULTS AND FINDINGS}

\section{Scenario description}

In designing the system, the mathematical model of two degree of freedom mass spring damper was derived to obtain the relationship between mass, spring, damper, force and actuator as shown in equation (1-4). This mathematical model was constructed by using block diagram in Simulink. Then the data of earthquake disturbance was taken as an example to make it as the force disturbance input to the building structure system. The data was taken based on real seismic that occurred at El Centro. The parameters of structural system and actuator that used in this simulation were shown in Table 2. After the structure system was complete, the controller was designed to implement to the system.

Table 2 System parameter.

\begin{tabular}{ccc}
\hline Parameter & Value/Unit & symbol \\
\hline Mass & $1.28 \mathrm{~kg}$ & $m_{1}, m_{2}$ \\
Damper & $15 \mathrm{~kg}$ & $c_{1}, c_{2}$ \\
Spring & $190 \mathrm{~kg}$ & $k_{1}, k_{2}$ \\
Thrust Constant & $2 \mathrm{~N} / \mathrm{A}$ & $K_{f}$ \\
Induce Voltage & $2 \mathrm{~A}$ & $K e$ \\
Resistance & $4.2 \Omega$ & $R$ \\
\hline
\end{tabular}

The analytical structural system was simulated based on the earthquake ground motion at El Centro with magnitude on $7.1 \mathrm{Mw}$ that killed 9 people on May 1940. The instrument that recorded the accelerogram was attached to the El Centro Terminal Substation Building's concrete floor, and not in a free-field location. The record might have under-represented the high frequency motions of the ground because of soil-structure interaction of the massive foundation with the surrounding soft soil (Schnable et al., 2009). The accelerogram was shown in Figure 7 with the record data until 30 second. The data acted as the earthquake ground motion to the building structure. The acceleration value was in range of $\pm 0.3 \mathrm{~g}$. The output of earthquake displacement data by implementing the mass spring damper system without controller was shown in Figure 8. The result output showed that the vibration waveform was reduced after implementing to the system with range in $\pm 0.01 \mathrm{~m}$.

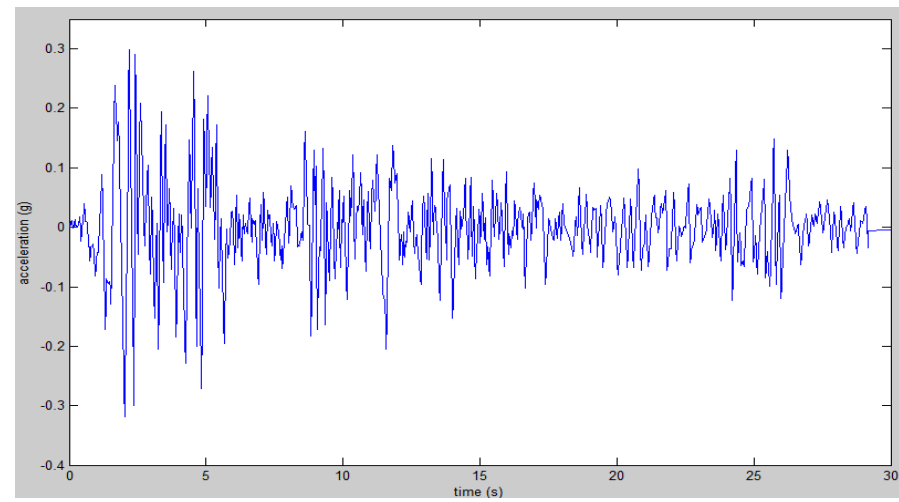

Fig. 7 El Centro earthquake accelerogram.

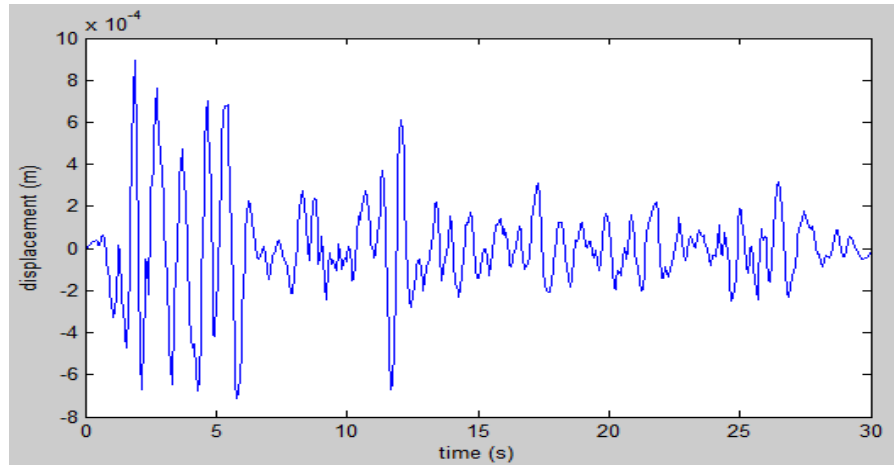

Fig 8 Uncontrolled system.

\section{RESULT AND DISCUSSION}

The simulation result was carried out by using Matlab/Simulink. The result was obtained for first storey displacement and second storey displacement by using fuzzy logic and sliding mode controller. These controllers were evaluated based on the performance in reducing the vibration displacement at both building floors. The result obtained was shown in Figure 9 and 10. Earthquake vibration for both storeys was reduced after controller was applied. As shown in Figure 9, sliding mode controller has best performance compared to fuzzy logic controller based on the range of vibration displacement. For the first storey, fuzzy logic controller has the maximum vibration of 0.6 $\mathrm{mm}$ while sliding mode controller, the maximum vibration was 0.02 $\mathrm{mm}$, compared to uncontrolled, the maximum vibration was $0.9 \mathrm{~mm}$. While the result for second storey as shown in Figure 10, the building vibration has the maximum with $1 \mathrm{~mm}$ for uncontrolled, the vibration was then reduced by using fuzzy logic with the maximum vibration value of $0.8 \mathrm{~mm}$ while by using SMC the vibration maximum wasis $0.2 \mathrm{~mm}$. It was observed that, sliding mode controller has lowest vibration graph with reduction percentage with uncontrolled was $77 \%$, while fuzzy logic reduction percentage was $33 \%$. Thus the controller was applicable to control building structure to prevent huge damage to building.

Figure 11 and 12 show the simulation result obtained from the output control voltage fuzzy logic and sliding mode controller. For fuzzy logic, the output control voltage was in range $\pm 0.3 \mathrm{~V}$ while SMC in range of $\pm 0.5 \mathrm{~V}$. This result showed that the limitation voltage used in the simulation as an input to the linear actuator was $\pm 0.5 \mathrm{~V}$. This value was recorded to make as the source for actuator in case the experimental was set up.

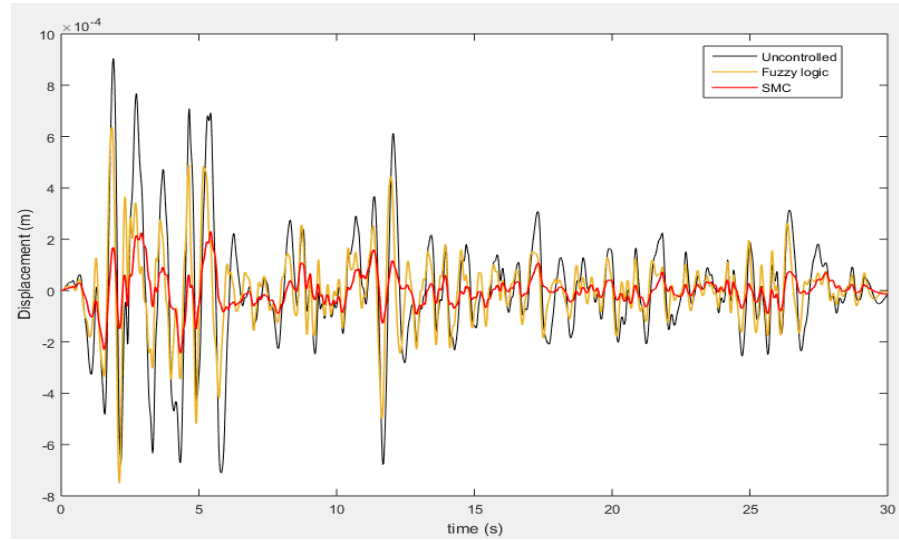

Fig. 9 First storey displacement waveform for uncontrolled and fuzzy logic control 


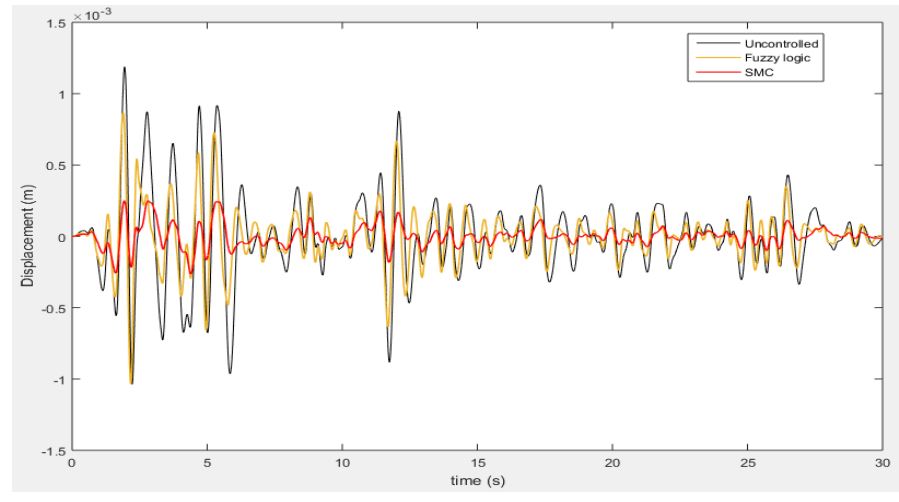

Fig. 10 Second storey displacement waveform for uncontrolled and fuzzy logic control.

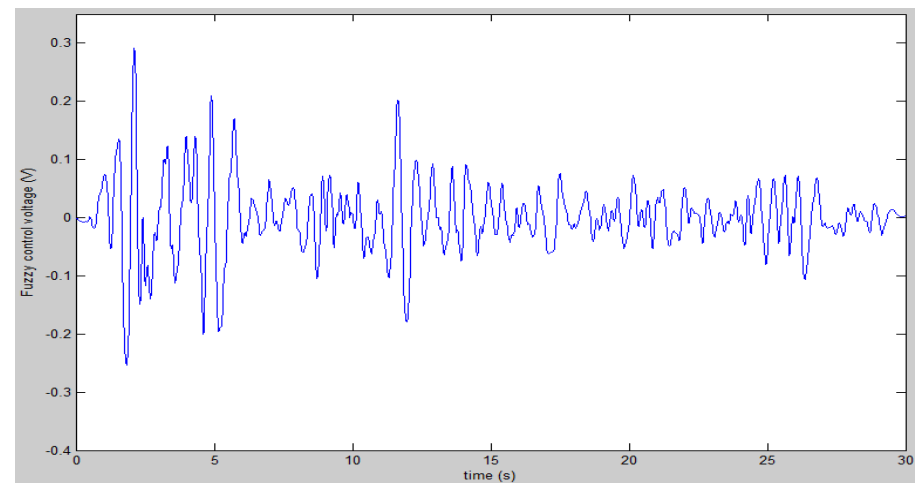

Fig. 11 Fuzzy output voltage.

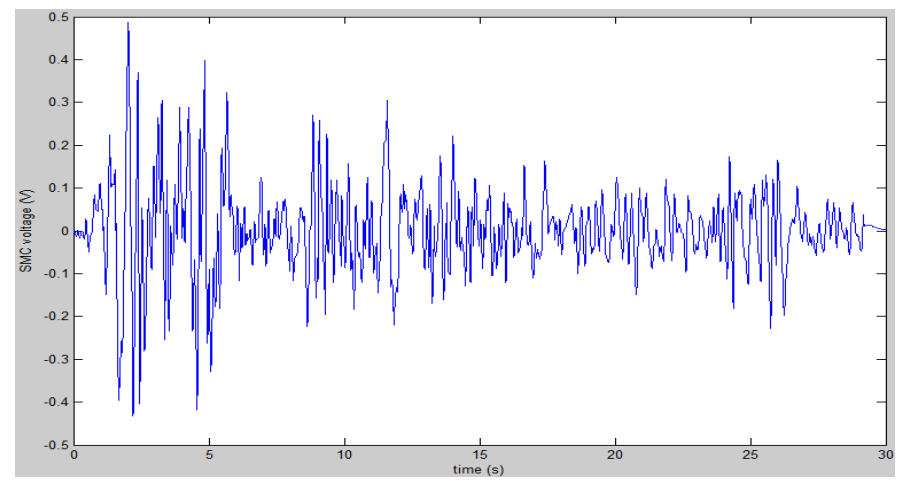

Fig. 12 SMC output voltage.

\section{CONCLUSION}

This paper used real seismic data as an input to mass spring damper system that obtained from El Centro earthquake that occurred in 1940. The structure system was controlled by using active control that located at the first building floor and using fuzzy logic and sliding mode controller to suppress the earthquake vibration. Both controllers were chosen based on the robustness characteristic. The simulation was success based on the simulation result. It was found that by using the controller, earthquake vibration could be reduced. However, by comparing between fuzzy logic and SMC, SMC has better performance compared to fuzzy logic controller. The experimental setup for the mass spring damper system would be performed later to further improvement besides of reducing the chattering in using sliding mode control to obtain the better performance.

\section{ACKNOWLEDGEMENT}

This research was supported financially by a research university grant (11H67) from the Universiti Teknologi Malaysia.

\section{REFERENCES}

Amini, F., Tavassoli, M. R. 2005. Optimal structural active control force, number and placement of controllers. Engineering Structures, 27, 9, 13061316.

Datta, T. 2003. A state-of-the-art review on active control of structures. ISET Journal of Earthquake Technology, 40, 1, 1-17.

Earthquake Report. 2016. 25 worst earthquakes in history. Retrieved from http://list25.com/25-worst-eartquake-in-history/(Accessed:2 Nov 2017)

Emelyanov, S. 1959. Control of first order delay systems by means of an astatic controller and nonlinear correction. Automatica Remote Control, 8, 983-991.

Fallah, N., Ebrahimnejad, M. 2013. Active control of building structures using piezoelectric actuators. Applied Soft Computing, 13, 1, 449-461.

Gioncu, V., Mazzolani, F. 2010. Earthquake Engineering for Structural Design: CRC Press.

Guclu, R. 2006. Sliding mode and pid control of a structural system against earthquake. Mathematical and Computer Modelling, 44, 1-2, 210-217.

GÜÇLÜ, R. 2003. Fuzzy logic control of vibrations of analytical multi-degreeof-freedom structural systems. Turkish Journal of Engineering and Environmental Sciences, 27, 3, 157-168.

Güney, M., Eşkinat, E. 2008. Optimal actuator and sensor placement in flexible structures using closed-loop criteria. Journal of Sound and Vibration, 312, 1-2, 210-233.

Jing-Jun, Z., Li-Ya, C., Wei-Ze, Y. 2009. Active vibration control for smart structure base on the fuzzy logic. Paper presented at the International Conference on Advanced Computer Control (ICACC '09), International Conference on IEEE, 231-235.

Liu, D., Yang, Y., Li, Q. 2003. Optimum positioning of actuators in tall buildings using genetic algorithm. Computers \& Structures, 81, 32, 2823 2827.

Maria, G., Selvaganesan, N., Kumar, B. A., Kapoor, S. 2015. Dynamic analysis and sliding mode vibration control for a two storeyed flexible building structure. In Control Communication \& Computing India (ICCC), 2015 International Conference on IEEE, 24-29.

McNamara, R. J. 1977. Tuned mass dampers for buildings. Journal of the Structural Division, 103, 9, 1785-1798.

Sambariya, D., Gupta, R. 2005 . Fast output sampling technique based speed controller for DC motor. National Conference on Power Engineering Practices \& Energy Management, 95-98.

Schnable, P. S., Ware, D., Fulton, R. S., Stein, J. C., Wei, F., Pasternak, S., et al. 2009. The b73 maize genome: Complexity, diversity, and dynamics. Science, 326, 5956, 1112-1115.

Sharma, M., Singh, S. 2014. Fuzzy logic based vibration control of a single degree of freedom system. In Engineering and Computational Sciences (RAECS), 2014 Recent Advances in IEEE, 1-6.

Shiba, K., Mase, S., Yabe, Y., Tamura, K. 1998. Active/passive vibration control systems for tall buildings. Smart materials and structures, 7, 5, 588.

Thenozhi, S., Yu, W. 2013. Advances in modeling and vibration control of building structures. Annual Reviews in Control, 37, 2, 346-364.

Yi, F., Dyke, S. J. 2000. Structural control systems: Performance assessment. Paper presented at the American Control Conference, 2000. Proceedings of the 2000, vol. 1, 6, 14-18. IEEE.

Yu, W., Thenozhi, S., Li, X. 2014. Stable active vibration control system for building structures using PD/PID control. IFAC Proceedings Volumes, 47, 3, 4760-4765.

Zhang, X. 2010. Study on fuzzy control algorithm of high-rise buildings structural vibration. In Mechanical and Electrical Technology (ICMET), $20102^{\text {nd }}$ International Conference on IEEE, 701-704. 